\title{
Biopsy of Heart
}

National Cancer Institute

\section{Source}

National Cancer Institute. Biopsy of Heart. NCI Thesaurus. Code C51794.

Removal of tissue from the heart for microscopic examination. 